\title{
Programa Saúde Auditiva do Escolar: uma integração entre pesquisae extensão
}

\author{
Thainá Ruth França de Farias ${ }^{1}$, Aryelly Dayane da Silva Nunes², Victor Vasconcelos de Barros ${ }^{3}$, Aline \\ Roberta da Silva Xavier ${ }^{4}$, Pierre Andrade Freire5, Ricardo Fernando Arrais ${ }^{6}$, Isabelle Ribeiro Barbosa7, \\ King Chung ${ }^{8}$, Sheila Andreoli Balen ${ }^{9}$
}

\begin{abstract}
Resumo: A audição é um dos sentidos mais significativos para a comunicação humana, de tal maneira que a sua ausência acarreta efeitos negativos no bem-estar e na qualidade de vida da população envolvida. Diante desse contexto, esse estudo teve como objetivo relatar a experiência das atividades de pesquisa e de extensão desenvolvidas no Programa Saúde Auditiva do Escolar (PSAE), voltadas à educação em saúde auditiva. Foram realizados testes auditivos em uma comunidade escolar e verificadas as alterações auditivas mais prevalentes nessa população. Os principais achados foram obstrução de orelhas por cerume e relato do uso frequente de fones de ouvido. Os resultados encontrados contribuíram para a realização da ação de extensão "Ouvir por toda a vida: Dia Mundial da Audição 2020", durante a qual foram realizadas quatro atividades por meio de recursos didáticos e lúdicos com essa população, sendo elas (1) "higienização das orelhas", (2) "mapa do barulho", (3) avaliação da intensidade do fone de ouvido com o auxílio da "Cocleannny", (4) roda de conversa com os escolares com o auxílio da "Alexa" (personagem virtual) e (5) roda de conversa com os professores, sobre os problemas mais frequentes detectados. Todas as atividades apresentaram bons resultados, além de engajamento por parte da comunidade escolar, contribuindo para que os escolares possam tomar decisões mais adequadas quanto aos hábitos deletérios antes praticados: excessiva utilização do fone de ouvido e ruído durante as aulas.
\end{abstract}

Palavras-chave: Transtornos da Audição; Estudantes; Educação em Saúde; Prevenção Primária

\section{School Auditory Health Program: an integration between research and extension}

Abstract: Hearing is one of the most significant meanings for human communication, so that its absence has adverse effects on the well-being and quality of life of the population involved. Given this context, this study aimed to report the experience of research and extension activities developed in the School Auditory Health Program (SAHP), focused on hearing health education. Hearing tests were carried out in a school community, and the most prevalent hearing disorders in this population were verified. The main findings were ear obstruction by cerumen and self-report of the frequent use of headphones. The results found contributed to the implementation of the extension action "Listening for life: World Hearing Day 2020", during which four interactive activities were carried out through didactic and ludic resources with this population, which are (1) "ear cleaning," (2) "noise map," (3) earphone intensity assessment with the help of "Cocleanny," (4) conversation with students with the help of the virtual character "Alexa" and (5) conversation with the teachers, all aiming to reduce the most frequent problems detected. All activities showed promising results and engagement by the school community, helping the students make more appropriate decisions regarding the harmful habits previously practiced, e. g. excessive use of the headset and noise during classes.

Keywords: Hearing Disorders; Students; Health Education; Primary Prevention

\author{
Originais recebidos em \\ de agosto de 2020 \\ Aceito para publicação em \\ 09 de março de 2021
}

1

Graduanda de Fonoaudiologia, Universidade Federal do Rio Grande do Norte (UFRN). Bolsista de Iniciação Científica, PROPESQ/UFRN. Pesquisadora do Lab. de Inovação Tecnológica em Saúde, LAIS/UFRN https://orcid.org/0000-0003-4715-1757

2

Doutoranda do Programa de Pós-Graduação (PPG) em Saúde Coletiva e Pesquisadora do LAIS/UFRN. https://orcid.org/0000-0002-3814-2675 3 Mestrando do PPG em Fonoaudiologia UFPB/UFRN, Pesquisador do LAIS/UFRN.

https://orcid.org/0000-0003-3227-3604

4

Graduanda de Fonoaudiologia e Bolsista PROEX/UFRN. Pesquisadora do LAIS/UFRN.

https://orcid.org/0000-0002-2326-2447

5

Mestrando do PPG em Gestão e Inovação em Saúde, UFRN.

https://orcid.org/0000-0003-1804-2383

6

Professor do PPG em Gestão e Inovação em Saúde, UFRN, Pesquisador do LAIS/UFRN.

https://orcid.org/0000-0002-9258-4263

7

Professora da Faculdade de Ciências da Saúde do Trairí (FACISA)/ UFRN, e PPG em Saúde Coletiva UFRN. https://orcid.org/000-0002-1385-2849 8

Audiologista, Professora da Northern Illinois University, Illinois, EUA.

https://orcid.org/0000-0001-5052-584X 9

Professora do PPG em Fonoaudiologia UFPB/UFRN.

Pesquisadora do LAIS/UFRN.

https://orcid.org/0000-0003-1353-4362

(autora para correspondência)

sheila@sheilabalen.com.br 


\section{Introdução}

A audição possibilita a interação com a sociedade, permitindo que as pessoas se relacionem, realizem suas atividades diárias, fiquem alertas aos perigos ao redor, e vivenciem os acontecimentos da vida, sendo assim muito importante para a comunicação humana (Correia \& Coelho, 2012; Organização Mundial da Saúde [OMS], 2016). Esse sentido está diretamente relacionado à capacidade de ouvir, compreender e transmitir as informações adquiridas, e é de suma importância para o desenvolvimento da linguagem, habilidades cognitivas e psicossociais das crianças (Fazito et al., 2008). Portanto, quaisquer alterações nesta via podem gerar consequências em diversos âmbitos da vida do indivíduo: social, emocional, acadêmico, psicológico e econômico (Manchaiah \& Stephens, 2013). Quando essas alterações ocorrem na infância, as consequências podem ser ainda mais impactantes sobre o desenvolvimento da criança.

Segundo a OMS (2018), 34 milhões de crianças no mundo vivem com dificuldades auditivas, das quais $60 \%$ são de causas evitáveis e em países de baixa e média renda. Nesse período da vida, ouvir sons e palavras é crucial para o aprendizado da linguagem falada, habilidades em leitura e matemática, desempenho acadêmico e para o engajamento social (American Speech-Language-Hearing Association [ASHA], 2015; OMS, 2016). Portanto, a deficiência auditiva pode provocar consequências biopsicossociais, como atrasos no desenvolvimento cognitivo e nas habilidades de fala e linguagem, privação sensorial, baixo desempenho acadêmico e problemas de interação social da criança (ASHA, 2015; Rodrigues et al., 2014). Em uma visão mais coletiva, pode-se dizer que perdas auditivas não tratadas afetam o desenvolvimento social e econômico de comunidades e países (OMS, 2016).

No contexto escolar, a integridade do sistema auditivo é essencial para que a criança tenha um bom desempenho. Por isso, é de grande importância a identificação das alterações auditivas em crianças em idade escolar, especialmente aquelas que estão passando pelo período de alfabetização (Farias et al., 2012; Tamanini et al., 2015). Por conseguinte, programas voltados à saúde auditiva devem ser implantados como parte da atenção primária em saúde, e são aconselhadas intervenções fonoaudiológicas direcionadas para a promoção da saúde auditiva (Lacerda, 2015).

No Brasil, o Programa Saúde do Escolar instituído em 2007 como uma ação interministerial entre Ministério da Saúde e Ministério da Educação salienta a relevância da atenção, promoção, prevenção e assistência em saúde, em conformidade com os princípios e diretrizes do Sistema Único de Saúde (SUS). Nesse contexto, é prevista a avaliação auditiva com a identificação de escolares com possíveis sinais de alteração, assim como ações de promoção da saúde auditiva (Lacerda et al., 2013). Devem ainda ser consideradas nessas ações as questões territoriais e, em consequência, o diagnóstico e o tratamento local em saúde (Decreto $n^{\circ} 6.286$, de 5 de dezembro de 2007, Portaria interministerial no 1.055, de 25 de abril de 2017). Portanto, a escola se torna um local ideal para a implantação de políticas públicas de educação à saúde.

A Triagem Auditiva Escolar é relevante para um bom rendimento escolar, pois pode agilizar o diagnóstico e a intervenção, oferecendo uma maior atenção à saúde auditiva dessa população (Colella-Santos et al., 2009; Tamanini et al., 2015). Em relação à intervenção e prevenção, a atuação fonoaudiológica deve visar enfrentar o problema de saúde através de ações coletivas, contribuindo para a melhora das condições de vida da população (Mendonça \& Lemos, 2011; Lacerda, 2015).

A partir dessas concepções, foram desenvolvidas as ações do Programa Saúde Auditiva do Escolar (PSAE), executadas em uma escola pública no município de Macaíba, localizado na região metropolitana de Natal, estado do Rio Grande do Norte. Nesse estado, a prevalência para a perda auditiva e fatores associados em escolares é de 16\% (Nunes, 2018), o que expressa a necessidade de educação em saúde nesta região. 
Na primeira etapa do desenvolvimento do trabalho ora descrito, foram realizadas ações de identificação das alterações auditivas; a partir dos resultados encontrados, foi realizada a segunda etapa, com ações educativas e lúdicas voltadas à promoção da saúde auditiva e à prevenção da perda auditiva para escolares e professores. Diante disso, o objetivo desse artigo foi relatar a experiência das atividades de pesquisa e extensão desenvolvidas no PSAE, voltadas à educação em saúde auditiva.

\section{Métodos}

Trata-se de um relato de experiência realizada no período de agosto a setembro de 2019 e em março de 2020, nos seguintes projetos: Projeto de Pesquisa "Validação de instrumento de audiometria automatizada utilizando o iPad", como etapa 1, e Projeto de Extensão "Programa Saúde Auditiva do Escolar: identificação e orientação", como etapa 2, ambos com aprovação do Comitê de Ética em Pesquisa em Seres Humanos da Universidade Federal do Rio Grande do Norte (UFRN) (CEP: n³.442.963). Na etapa 2 foram incluídas ações do Dia Mundial da Audição, com cadastro da mesma na Organização Mundial de Saúde [OMS] (2020). A ação, realizada em uma escola pública municipal no bairro central do município de Macaíba no estado do Rio Grande do Norte, contou com participação de pesquisadora internacional da Fulbrighte promoveu ações de ensino, pesquisa e extensão, envolvendo alunos de graduação e pós-graduação em Fonoaudiologia da UFRN.

Na etapa 1, foram realizadas a coleta de informações referentes às condições auditivas dos escolares (referidas pelos escolares, pais e professores), a avaliação audiológica (audiometria tonal, imitanciometria, emissões otoacústicas) e a avaliação com otorrinolaringologista, quando necessário. Essa etapa foi realizada com a participação de pesquisadora internacional, que objetivou avaliar a audição de escolares na região metropolitana de Natal. Houve a participação de 53 voluntários - alunos da graduação e pós-graduação em Fonoaudiologia, fonoaudióloga pós-graduanda em Saúde Coletiva, e docentes e colaboradores do Departamento de Fonoaudiologia da UFRN. A equipe participou de treinamento com duração de 14 horas, previamente à aplicação de todos os testes com a pesquisadora internacional. A coleta de dados deu-se de forma intensiva, durante o mês de setembro de 2019, no turno matutino e vespertino, procedimento que foi idealizado pela pesquisadora internacional, que forneceu os equipamentos, treinou e calibrou todos os participantes antes da coleta de dados, bem como forneceu os equipamentos necessários à sua rea lização antes dos procedimentos da coleta e esteve presente em todos os momentos da pesquisa.

Foram atendidos os critérios das Normas e Diretrizes Brasileiras preconizadas pelo Conselho Nacional de Saúde (Resoluções n 466/12 e 510/16) por meio da assinatura do Termo de Consentimento Livre e Esclarecido (TCLE) pelos responsáveis, bem como do Termo de Assentimento Livre e Esclarecido (TALE) pelos escolares antes da realização dos testes. Além disso, todas as crianças receberam, por escrito, o resultado da triagem auditiva e o encaminhamento para o Serviço de Referência em Saúde Auditiva do SUS de Macaíba, no caso dos que apresentaram alterações.

A partir dos dados de alterações audiológicas e das principais queixas auditivas na etapa 1, foi planejada a intervenção executada na etapa 2, por meio do evento "Ouvir por toda a vida: Dia Mundial da Audição 2020", proposto pela OMS (2020). Na etapa 1 estiveram envolvidos 42 alunos da graduação, 6 da pós-graduação e 5 professores universitários. Na etapa 2, estiveram envolvidos três alunos da graduação, quatro da pósgraduação e um professor universitário, realizando-se cinco atividades de educação em saúde com os escolares e professores. Em todas as etapas, a participação dos escolares foi livre, sendo necessário apenas a assinatura do TCLE e do TALE para a primeira etapa, e as duas ocorreram em ambiente escolar nos turnos matutino e vespertino. 


\section{Relato das a tividades}

Na etapa 1 foram avaliados 294 escolares por meio dos procedimentos abaixo citados:

1. Otoscopia (Welch Allyn MacroView): para verificar as condições da orelha externa e média;

2. Timpanometria (EroScan Pro): para verificar as condições da orelha média;

3. Emissões otoacústica por produto de distorção (EroScan Pro): para verificação das condições das células ciliadas na orelha interna;

4. Audiometria tonal (EARScan 3): para verificar a sensibilidade auditiva;

5. Questionário sobre saúde, cuidados e educação auditiva.

Todos os procedimentos foramaceitos pela comunidade escolar (escolares, professores, direção, coordenação, funcionários, pais/responsáveis) e as intercorrências prevalentes constatadas durante essa etapa foram:

a) orelha com obstrução por cerume: esse resultado foi baseado na análise do meato acústico externo por meio da otoscopia, no qual a orelha era considerada com obstrução ao ser encontrada alteração, que poderia incluir a presença de cera em quantidade maior ou igual a 75\% do diâmetro do conduto, algum corpo estranho, perfuração, e/ou qualquer outra alteração que necessitasse de cuidados especiais, sendo detectada em $16 \%$ das orelhas avaliadas;

b) autorrelato do uso frequente de fones de ouvido: nesse ponto, $54 \%$ dos escolares avaliados que responderam ao questionário relataram utilizar esse equipamento, sendo comum o relato de uso em intensidade máxima.

O treinamento para essa etapa tambémpossibilitou conhecimento de diferentes instrumentose métodos para avaliação auditiva aos graduandos e pós-graduandos, sendo realizados testes entre os próprios escolares, o que permitiu a compreensão e experiência de cada teste na visão do paciente.

As ações de educação em saúde auditiva foram planejadas e desenvolvidas com ba se na faixa etária, além de conhecimento das necessidades envolvidas na etapa 1 (testes supracitados e relato da comunidade escolar).

$\mathrm{Na}$ etapa 2, estiveram envolvidos aproximadamente 400 escolares e 25 professores do ensino fundamental. As atividades realizadas nessa etapa foram divididas em 5 estratégias de intervenção e serão relatadas a seguir.

A primeira atividade desenvolvida teve a finalidade de esclarecer dúvidas e orientar a população escolar sobre a higienização das orelhas. Para esta etapa foi desenhada, em uma cartolina, uma orelha externa e acoplado um tubo plástico transparente, simulando o meato acústico externo. Com objetivo de representa r o cerume, foi utilizada massa para E.V.A. e uma haste flexível gigante, a qual foi confeccionada com tubo de cartolina e com esferas de algodão nas extremidades. Para realizar a atividade, um voluntário (escolar ou professor) deveria tentar retirar o "cerume" utilizando o tubo com algodão para demonstrar os prejuízos do uso inadequado de hastes flexíveis. Como resultado, foi observado engajamento, não só dos escolares, como também de professores, que tentaram sem sucesso remover todo cerume do modelo de meato acústico externo, compreendendo as implicações negativas do uso de hastes flexíveis com pontas de algodão.

A segunda atividade desenvolvida, intitulada como "Mapa do barulho", buscou explicar o conceito das características acústicas (diferenças de intensidade e frequência dos sons) e dos impactos do ruído competitivo na audição e compreensão auditiva. Nesta atividade, foi construído um audiograma em cartolina e foi utilizado imagens representativas de objetos e animais que emitem sons, em diferentes intensidades e frequências, que deveriam ser coladas em seu respectivo lugar no audiograma. Após explicação das características do audiograma, foram convidados dois voluntários, vendados, para colar as figuras no local correspondente do 
audiograma, com o auxílio de instruções orais da turma, em um momento com ruído competitivo para dificultar e, em outro momento, no silêncio para fazer a comparação da execução da tarefa (Figura 1).

A terceira atividade objetivou avaliar a intensidade da utilização dos fones de ouvido pelos escolares e realizar orientação de cuidados em saúde auditiva, baseada na intensidade observada. Para esse fim, utilizou-se uma manequim com um decibelímetro acoplado, desenvolvida a partir do "The Jolene cookbook"do Programa Dangerous Decibels (Martin et al., 2013), que em português significa "Decibéis Perigosos", nomeada pela equipe deste projeto por "Cocleanny" (Figura 2). Após, foram realizadas orientações com base na intensidade observada (por exemplo, um aluno que utiliza o fone em intensidade de $85 \mathrm{~dB}$ era comparado à intensidade emitida pelo liquidificador). Essa atividade teve um alto índice de engajamento, visto que muitos dos escolares utilizavam fones de ouvido e, quando questionados, declararam enfaticamente a sua utilização em intensidade máxima, sendo registrado na "Cocleanny" saídas de até 93 dBNPS.
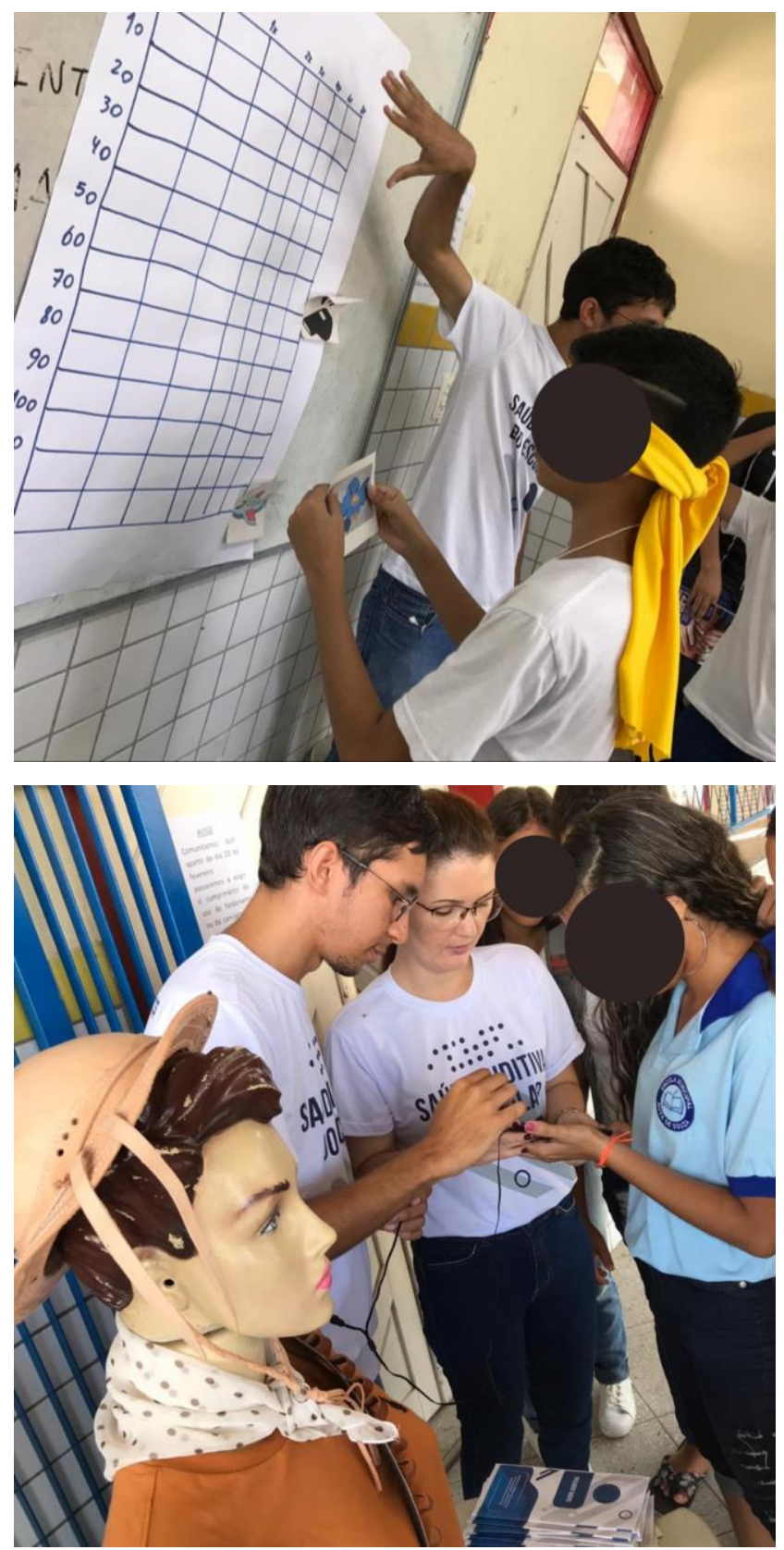

Figura 1. Aluno realizando a atividade "mapa do barulho", utilizada como recurso didático para explanação sobre as características dos sons.

Figura 2. Grupo de escolares aferindo a intensidade no uso do fone de ouvido com a "Cocleanny". 
A quarta atividade foi uma roda de conversa com composição livre. Foram formados pequenos grupos, garantindo uma possibilidade de interação com a maior quantidade possível de escolares que eram convidados a conversarcom a assistente pessoal "Alexa" e previamente programada para responder perguntas quanto aos cuidados em saúde auditiva (Quadro 1). O seu uso na escola teve a finalidade de contribuir com o esclarecimento de dúvidas que surgiram durante o uso da "Cocleanny" , como uma ferramenta tecnológica que contribuísse para o interesse e interação dos escolares. A inserção da "Alexa" gerou curiosidade nos escolares e momentos de interação descontraídos, uma vez que a assistente só respondia adequadamente às perguntas de acordo com o que foi programado; as respostas aleatórias, além de divertidas para os escolares, geraram oportunidades de orientações em saúde auditiva a partir do interesse deles. Foi observado maior engajamento dos escolares e professores com os extensionistas envolvidos na execução da estratégia.

A quinta atividade envolveu a orientação dos professores da escola em questão. Participaram 25 professores divididos em uma turma matutina e outra vespertina, envolvidos em uma 'roda de conversa' com a equipe, na qual foram abordados sinais e sintomas da deficiência e outras alterações auditivas e seus impactos acadêmicos, além de possíveis ações do professor na identificação dos distúrbios auditivos e estratégias de comunicação. Foi utilizada a estratégia de ditado com palavras de baixa frequência, dentro da realidade dos professores, sem leitura orofacial e com ruído competitivo, como forma de dinâmica, com o objetivo de que fosse possível entender que os escolares podem ter as mesmas dificuldades de compreensão que os professores tiveram na dinâmica anterior, na tarefa diária de compreender novos assuntos (Figura 3). A partir desta estratégia de sensibilização, a equipe abordou com os professores as melhores maneiras de comunicação nas suas ações pedagógicas. Além disso, a apresentação dos resultados da pesquisa a esses profissionais contribuiu para a integração da comunidade - universidade.

Os professores também estiveram envolvidos em todas as outras atividades realizadas com os escolares, e os resultados da intervenção foram aferidos a partir do relato oral dos participantes.

\section{Discussão}

O presente estudo relata a experiência das ações de pesquisa que embasaram ações de educação em saúde auditiva realizadas em ambiente escolar. Por meio de cinco atividades envolvendo escolares, professores e/ou coordenação pedagógica e direção escolar, houve aumento do envolvimento da comunidade na promoção da saúde auditiva e na proteção da audição em todas as faixas etárias.

Consoante o artigo 196 da Constituição Federal Brasileira (1988), o princípio da isonomia garante, a todos os indivíduos, políticas sociais que reduzam o risco de doença. Posto isso, um dos grandes desafios na formação do profissional da saúde é prepará-lo para lidar com as necessidades da população (Brito, 2016). Portanto, a extensão universitária é uma ferramenta de potente transcendência no aprendizado das co ndições sociais, pois promove a autonomia do estudante, a elevação do pensamento crítico e reflexivo sobre ações de educação em saúde. Ainda contribui de forma recíproca para o corpo social envolvido, que será beneficiado por meio da ampliação dos serviços a ele prestados, e para o graduando e pós-graduando, que serão beneficiados com maior aprendizado, em consonância com a ampliação das habilidades profissionais e humanitárias, com conhecimentos que não se limitam à sala de aula (Santos et al., 2016), de forma a não tornar a formação e especialização profissional tão somente tecnicista. 
Quadro 1. Conteúdo programado na Assistente Pessoal "Alexa", utilizada para esclarecer as dúvidas dos escolares quanto a sua saúde auditiva.

\begin{tabular}{|c|c|}
\hline Perguntas & Respostas \\
\hline $\begin{array}{l}\text { "Alexa", posso usar } \\
\text { cotonete? }\end{array}$ & $\begin{array}{l}\text { Sim, você pode usar o cotonete, mas não pode colocar dentro do ouvido, } \\
\text { apenas passá-lo por fora. }\end{array}$ \\
\hline $\begin{array}{l}\text { "Alexa", por que não } \\
\text { posso colocar cotonete } \\
\text { dentro do ouvido? }\end{array}$ & $\begin{array}{l}\text { Porque você poderá empurrar a cera do ouvido e ter uma rolha de cera. } \\
\text { Esta rolha pode deixar você ouvindo menos. }\end{array}$ \\
\hline $\begin{array}{l}\text { "Alexa", como chama a } \\
\text { sujeira do ouvido? }\end{array}$ & $\begin{array}{l}\text { Não há sujeira no ouvido. O que você vê chama-se cerume, ou cera do } \\
\text { ouvido. }\end{array}$ \\
\hline $\begin{array}{l}\text { "Alexa", por que tem } \\
\text { cera no ouvido? }\end{array}$ & Para proteger o seu ouvido, principalmente, de insetos. \\
\hline $\begin{array}{l}\text { "Alexa", posso usar fones } \\
\text { de ouvido para ouvir } \\
\text { música? }\end{array}$ & $\begin{array}{l}\text { Sim, você pode, mas deve ter cuidado com o volume que você usa. Deixe } \\
\text { em um volume médio, alterne os ouvidos e não o use por muitas horas } \\
\text { seguidas. }\end{array}$ \\
\hline $\begin{array}{l}\text { "Alexa", qual o volume } \\
\text { que posso ouvir música? }\end{array}$ & $\begin{array}{l}\text { Em um volume baixo ou médio. Nunca o coloque em volume alto, porque } \\
\text { pode gerar problemas para você ouvir. }\end{array}$ \\
\hline $\begin{array}{l}\text { "Alexa", como eu sei se o } \\
\text { volume do fone está } \\
\text { forte? }\end{array}$ & $\begin{array}{l}\text { Se outras pessoas que estiverem a um metro de distância de você } \\
\text { disserem que estão ouvindo a música, isso significa que está forte. Abaixe } \\
\text { o volume e proteja o seu ouvido, mantendo a sua audição saudável. }\end{array}$ \\
\hline "Alexa", que dia é hoje? & $\begin{array}{l}\text { Hoje estamos comemorando o Dia Mundial da Audição. Este dia é } \\
\text { recomendado pela Organização Mundial da Saúde para que possamos } \\
\text { realizar atividades de orientação às pessoas sobre como manter sua } \\
\text { audição saudável. Este ano o tema da campanha é "Não deixe a perda da } \\
\text { audição limitar você. Ouvir por toda a vida". Assim, siga as orientações que } \\
\text { estamos dando a você e mantenha sua audição saudável. }\end{array}$ \\
\hline $\begin{array}{l}\text { "Alexa", qual o problema } \\
\text { no ouvido se usar o fone } \\
\text { de ouvido em volume } \\
\text { muito forte? }\end{array}$ & $\begin{array}{l}\text { Você poderá vir a ter uma perda auditiva. Esta perda auditiva é irreversível, } \\
\text { porque suas células na cóclea podem morrer ao longo do tempo que você } \\
\text { estiver ouvindo o som do seu fone de ouvido em volume muito forte. } \\
\text { Quanto mais forte for o som, menos tempo você pode ficar exposto a ele. } \\
\text { Sons acima de } 85 \text { decibéis por oito horas podem vir a causar perda da } \\
\text { audição ao longo do tempo. }\end{array}$ \\
\hline
\end{tabular}




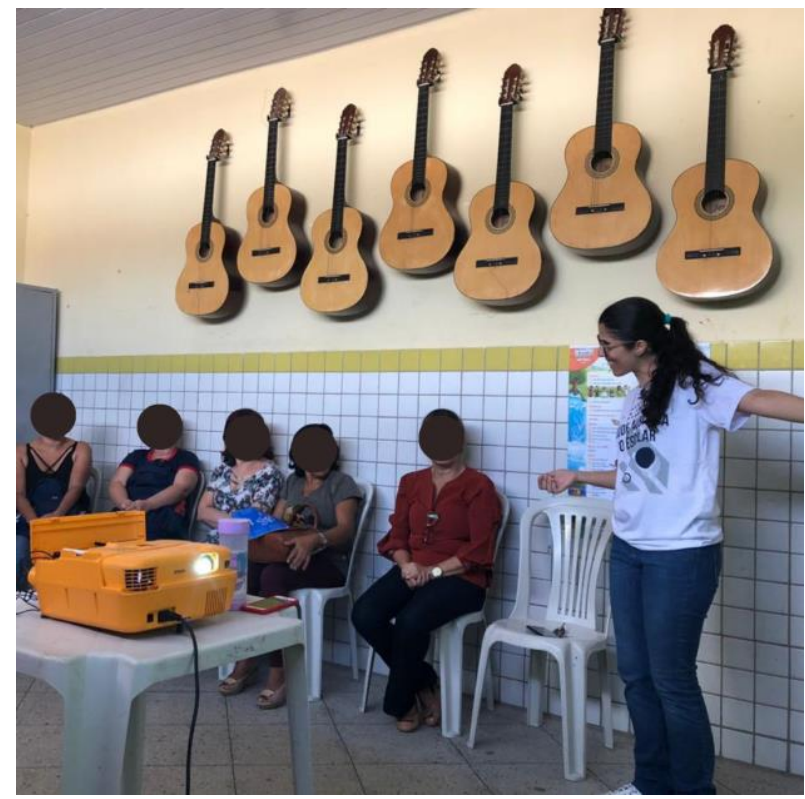

Figura 3. Grupo de professores participando da quarta atividade, na qual foi realizada orientações sobre saúde auditiva e estratégias de comunicação em sala de aula.

Além disso, o ambiente escolar é reconhecido como apropriado ao desenvolvimento de ações de educação em saúde (Couto et al, 2016), o que também contribui à formação da graduação e pós-graduação na integração do ensino-pesquisa-extensão. Para que as ações no ambiente escolar se concretizem, é necessário o comprometimento da comunidade escolar - escolares, professores, funcionários e comunidade externa (Couto et al, 2016). É relevante ainda que as ações no ambiente escolar considerem os contextos escolar e social, o diagnóstico local em saúde e a capacidade operativa em saúde (Portaria interministerial n 1.055, de 25 de abril de 2017), assim como foram considerados nas etapas 1 e 2 . As ações em saúde realizadas no ambiente escolar incorporam a intersetorialidade descrita no Programa Saúde na Escola (PSE), instituído em 2007 como uma política interministerial entre saúde e educação (Decreto n 6.286 , de 5 de dezembro de 2007).

Segundo o Ministério da Saúde (S. d.), as ações de saúde auditiva no âmbito escolar consistem na integração entre educação e saúde, bem como a capacitação dos professores para detectar essas dificuldades e serem os mediadores no cuidado e atenção à saúde auditiva do escolar. Dessa forma, essas ações se tornam indispensáveis, ao reconhecer os transtornos que a deficiência auditiva traz ao indivíduo, seja no âmbito acadêmico (Ávila, 2017), laboral (Freitas et al., 2017), ou na conquista de outros direitos sociais.

Vale salientar que a falta de compreensão sobre os cuidados com a saúde auditiva impacta o reconhecimento do agravo que sua ausência causa, fazendo com que o indivíduo desenvolva hábitos deletérios que poderiam ser evitados desde a infância (Sobel \& Meikle, 2008). Todavia, uma vez o comportamento aprendido, ele é naturalizado e reproduzido (Bourdieu, 1974), por isso a importância de que ações em saúde sejam realizadas nessa faixa etária. Dessa forma, todas as atividades desenvolvidas visaram atrair a atenção dos escolares e professores para adquirissem conhecimentos acerca dos cuidados em saúde auditiva através de estratégias lúdicas e de fácil compreensão, baseadas nas dificuldades específicas daquela população, identificadas na etapa 1 do projeto, como a diminuição da intensidade no uso dos fones de ouvido, e os cuidados para evitar o acúmulo de cerume.

Parte das atividades realizadas para a educação em saúde no ambiente escolar foram de baixa densidade tecnológica, como o "mapa dos sons" e a "higienização das orelhas", que se mostraram como atividades efetivas na promoção de saúde auditiva, como a poluição sonora dentro da escola. Dreossi e MomensohnSantos (2005) dividiram esses ruídos em três grupos correspondentes ao ruído externo à escola, externo à sala de aula, e interno à sala de aula, este último originado da comunicação dos escolares no momento da aula e 
dos ruídos emitidos por equipamentos diversos. Na tentativa de ultrapassar os ruídos existentes, o professor necessita falar com mais intensidade, com o objetivo de ser ouvido e compreendido, o que acarreta impactos negativos para sua saúde, em especial, alterações vocais (Silva, 2018). Segundo Santos et al. (2012), o conforto acústico relaciona-se com a ausência de sons indesejados, e é necessário em ambientes de atividades cognitivas. Para o aluno, a ausência desse conforto acústico pode afetar a atenção (Forns et al., 2016), dificuldade de escrita e leitura (Santos, et al., 2012) e a comunicação com o professor (Libardi et al., 2006).

Após a realização das atividades, os professores relataram que os escolares se tornaram mais conscientes sobre os danos da poluição sonora e reduziram o ruído. Tais ações são de extrema importância para que a criança e o adolescente possam ter uma conscientização no que se refere a sua saúde auditiva, diminuindo os impactos que a perda auditiva adquirida por hábitos deletérios (e evitáveis) possa causar futuramente.

A obstrução do meato por cerume foi a maior causa de alterações auditivas evidenciada na Etapa 1 da pesquisa. Mesmo que sintomas não sejam relatados, a atualização da Diretriz de Prática Clínica: cera de ouvido (Schwart et al., 2017) recomenda a remoção do cerume por profissional capacitado, sempre que identificada. Caso não seja removida, seu excesso pode acarretar a diminuição do limiar auditivo (Chandler, 1964) e, consequentemente, ampliar as dificuldades escolares, o que evidencia a necessidade de intervenção.

O uso dos fones de ouvido sem preocupação com a duração do uso ou o nível de exposição é comum entre os adolescentes (Marques et al., 2015), sendo o hábito deletério mais observado na escola em questão, o que aponta a necessidade de intervir precocemente nesses hábitos. A educação em saúde torna-se uma ferramenta que pode ser utilizada para essa finalidade. Oliveira et al. (2018) relatam diminuição da média da relação sinal/ruído das emissões otoacústicas por produto de distorção, na frequência de $5.000 \mathrm{~Hz}$ em jovens que ouvem música amplificada, o que causa danos irreversíveis a longo prazo. Apesar da proibição do uso de fones na escola, alguns escolares relataram fazer uso do mesmo apenas nesse local, o que também contribui para a desatenção durante o momento de aula, além da exposição a elevados níveis de pressão sonora em decorrência do ruído ambiental e da intensidade de uso dos fones de ouvido.

Com a ajuda da "Cocleanny", muitos escolares se surpreenderam ao fazer-se um comparativo entre a intensidade utilizada no fone e um ruído de mesma intensidade. Percebeu-se que, antes das orientações, os escolares consideravam os sons de alta intensidade como algo que os proporcionava sensações prazerosas, relato imediatamente modificado após a comparação dessas intensidades como sons prejudiciais. A "Alexa" como assistente pessoal da "Cocleanny" foi notada de forma ímpar pelos escolares, por ser uma tecnologia desconhecida, além de proporcionar uma situação lúdica. Por outro lado, observou-se a necessidade de programar a "Alexa" com respostas mais concisas e objetivas, considerando possíveis variantes de linguagem nessa programação principalmente na estruturação sintática e de vocabulário, para inserir estruturas linguísticas mais próximas à realidade dos escolares. Em virtude da inteligência artificial, a programação da "Alexa" para outras ações também poderá ser aprimorada, facilitando a efetividade do seu uso no contexto de educação em saúde em futuras aplicações, por não apresentar custo elevado, considerando a quantidade de escolares que podem ser alcançados a partir dessas ações. Contudo, destaca-se a necessidade de conexão de internet que, nesse ambiente, era disponível. Portanto, este é um aspecto que pode limitar o seu uso na educação em saúde.

Os resultados positivos obtidos com as atividades de baixa densidade tecnológica (higienização das orelhas, mapa do barulho, roda de conversa) foram também alcançados entre aquelas com maior densidade tecnológica associada - "Alexa" e "Cocleanny". Contudo, destaca-se que, nos dois cenários, o diálogo e as orientações verbais foram determinantes para os bons resultados das ações, independentemente da ferramenta escolhida. A aceitação e os bons resultados observados nas ações provavelmente estão 
relacionados ao fato de que as ações serem baseadas na realidade da escola, possivelmente gerando maior engajamento da comunidade escolar - escolares, professores, familiares.

Durante a roda de conversa com os professores, foi abordada a importância da audição para o aprendizado e para o desempenho escolar, assim como sinais e sintomas de alterações auditivas e o fluxo de encaminhamento na rede de saúde do SUS. A dinâmica de ditado com palavras de baixa frequência, sem apoio visual e com ruído competitivo, foi utilizada como base para orientação das estratégias de comunicação, o que gerou sensibilização dos professores para a escuta das orientações. Fernandes et al. (2018) citam a relevância de orientar os professores, pois os mesmos têm dificuldades de como instruir os escolares para tornar o ambiente silencioso.

Convém ressaltar, também, que o relato oral da comunidade escolar que pa rticipou da etapa 2 do estudo pode constituir uma limitação por não ter sido mensurada a efetividade das ações de forma objetiva. A liberdade de participação nas atividades propostas nas etapas 1 e 2 pode ter atraído mais escolares e professores com queixas auditivas e/ou mais dúvidas acerca da temática. Apesar dessas limitações, os benefícios da ação foram evidentes para a formação de graduandos e pós-graduandos, assim como para a comunidade escolar, os quais favoreceram a integração ensino-pesquisa-extensão.

Diante das experiências supracitadas, depreende-se, portanto, que a educação em saúde, por meio de ações de extensão universitária em ambiente escolar, é extremamente relevante para a comunidade envolvida, pois acarreta a autonomia da população para a obtenção do direito à saúde, bem como o conhecimento acerca dela, além de uma formação mais humanista dos graduandos e pós-graduandos. Todavia, nem todas as instituições de educação primária e secundária têm a oportunidade de participar dessa vivência, tanto pela distância física entre Universidade e Escola, quanto pelo pouco investimento em políticas públicas para fomentar essa prática no território nacional, e pela importância dada a essa questão pelos professores universitários, o que gera a necessidade de expandir o conhecimento sobre os benefícios mútuos que são gerados com essa experiência.

Dessa forma, para transpor as barreiras à educação em saúde, é necessário um olhar mais pertinente de enfrentamento por parte do Ministério da Educação, em parceria com o Ministério da Saúde e das Universidades Federais, para potencializar a formação profissional em saúde, em consonância com as práticas humanitárias que decorrem das ações de extensão, para todo o contingente populacional dentro desses ambientes.

\section{Conclusão}

Por meio desse relato evidenciou-se que as etapas de pesquisa e intervenções foram complementares, fornecendo informações, de forma lúdica, sobre a importância dos cuidados auditivos. Assim, os resultados demonstram que a relação entre ações de pesquisa e extensão são indissociáveis, e sua associação possibilitou que a intervenção de educação em saúde fosse direcionada às necessidades da população. Além disso, os graduandos e pós-graduandos agregaram experiências teórico-práticas à sua formação, à parte da inserção nas atividades de pesquisa e extensão per si. Também se evidenciou que as estratégias com tecnologia leve e acessíveis ao contexto escolar podem gerar bons resultados para a educação em saúde, unindo-as, quando possível, a ferramentas de maior densidade tecnológica, como a "Cocleanny" e a assistente pessoal "Alexa", utilizadas nesse estudo.

\section{Agradecimentos}

Agradecemos à Escola Municipal e a seus funcionários pela receptividade, aos demais alunos, do Curso de Fonoaudiologia e do Programa Associado de Pós-Graduação em Fonoaudiologia entre UFPB e UFRN que 
auxiliaram no momento da pesquisa e da ação e ao Laboratório de Inovação Tecnológica em Saúde, Programa de Pós Graduação em Fonoaudiologia e à Secretaria de Educação a Distância, da Universidade Federal do Rio Grande do Norte, pelo auxílio na logística do projeto.

\section{Con tribuições de cada autor}

Os autores T.R.F.F., A.D.S.N., A.R.X.S., V.V.B. e P.A.F. executaram as atividades práticas do projeto e escreveram o texto final; R.F.A., I.R.B e K.C. contribuíram com o texto final, e S.A.B. realizou as atividades práticas do projeto, contribuiu com o texto final, bem como a concepção, coordenação e acompanhamento de todas as etapas da execução e orientação do projeto.

\section{Referências}

American Speech-Language-Hearing Association (2015). Effects of hearing loss on development. [S. I.]: ASHA. Recuperado de https://www.asha.org/siteassets/uploadedFiles/AIS-Hearing-Loss-Development-Effects.pdf

Ávila, F.P. (2017). Inclusão de pessoas com deficiência auditiva no ensino superior: Um relato de experiência (Trabalho de Conclusão de Curso). Universidade Federal do Pampa, Jaguarão, Brasil. Recuperado de http://dspace.unipampa.edu.br/handle/riu/2361

Bourdieu, P. (1974). A economia das trocas simbólicas (p.58). São Paulo: Perspectiva.

Brito, E. A. (2016). Saberes e práticas de enfermeiros da Estratégia Saúde da Família sobre o consumo de álcool e outras drogas por pessoas idosas (Dissertação de Mestrado). Universidade Federal do Piauí, Teresina, Brasil. Recuperado de https://repositorio.ufpi.br/xmlui/handle/123456789/713

Chandler, J. R. (1964). Partial occlusion of the external auditory meatus: Its effect upon air and bone conduction hearing acuity. The Laryngoscope, 74(1), 22-54.

Colella-Santos, M. F., Bragato, G. R., Martins, P. M. F., \& Dias, A. B. (2009). Triagem auditiva em escolares de 5 a 10 anos. Revista CEFAC, 11(4), 644-653.

Correia, R. B. F., \& Coelho, J. M. S. (2012). Ações em saúde auditiva escolar no município de Sobral-CE: Percepção de fonoaudiólogos. Revista Brasileira em Promoção da Saúde, 25(2), 228-234.

Couto, A. N., Kleinpaul, W. V., Borfe, L., Vargas, S. C., Pohl, H. H., \& Krug, S. B. F. (2016) O ambiente escolar e as ações de promoção da saúde. Cinergis, 17(1), 378-383.

Dreossi, R. C. F., \& Momensohn-Santos, T. O. (2005) Ruído e sua interferência sobre estudantes em uma sala de aula: Revisão de literatura. Pró-Fono Revista de Atualização Científica, 17(2), 251-258.

Farias, V. V., Camboim, E. D., Azevedo, M. F. D., \& Marques, L. R. (2012). Ocorrência de falhas na triagem auditiva em escolares. Revista CEFAC, 14(6), 1090-1095.

Fazito, L. T., Lamounier, J. A., Godinho, R. N., \& Melo, M. D. C. B. D. (2008). Triagem auditiva neonatal e o diagnóstico precoce das deficiências auditivas na criança. Revista Médica de Minas Gerais, 18, 61-66.

Fernandes, L. V. S.; Medeiros, I. S.; Paz, M. C. P.; Araújo, P. V., \& Pessoa, V. S. A. (2018). Atitudes frente ao ruído no ambiente escolar: Uma análise com estudantes do ensino médio. In Atena Editora. (Org.). Políticas Públicas na Educação Brasileira: Formação de Professores e a Condição do Trabalho Docente. (pp. 54-66). 8 ed. Ponta Grossa, PR: Atena Editora.

Forns, J., Dadvand, P., Foraster, M., Alvarez-Pedrerol, M., Rivas, I., López-Vicente, M., ... \& Grellier, J. (2016). Trafficrelated air pollution, noise at school, and behavioral problems in Barcelona schoolchildren: A cross-sectional study. Environmental Health Perspectives, 124(4), 529-535.

Freitas, G. R., Maranhão, T. L. G., \& Félix, W. M. (2017). A Deficiência Auditiva e a possibilidade de inclusão no mercado de trabalho. ID online Revista Multidisciplinar e de Psicologia, 11(34), 184-218.

Lacerda, A. B. M. (2015). Audição no contexto da educação: Práticas voltadas à promoção e à prevenção. In E. M. Boéchat, P. L. Menezes, C. M. Couto, A. C. F. Frizzo, R. C. Scharlach, \& A. R. T. Anastasio (Eds.) Tratado de Audiologia. (pp. 414-424). Rio de Janeiro: Guanabara Koogan.

Lacerda, A. B. M. D., Soares, V. M. N., Goncalves, C. G. D. O., Lopes, F. C., \& Testoni, R. (2013). Oficinas educativas como estratégia de promoção da saúde auditiva do adolescente: Estudo exploratório. Audiology-Communication Research, 18(2), 85-92. 
Libardi, A., Cláudia, G. D. O., Vieira, T. P., Silverio, K. C., Rossi, D., \& Penteado, R. Z. (2006). O ruído em sala de aula e a percepção dos professores de uma escola de ensino fundamental de Piracicaba. Distúrbios da Comunicação, 18(2), 167178.

Manchaiah, V. K., \& Stephens, D. (2013). Perspectives on defining 'hearing loss' and its consequences. Hearing, Balance and Communication, 11(1), 6-16.

Marques, A. P. C., Miranda Filho, A. L., \& Monteiro, G. T. R. (2015). Prevalência de perda auditiva em adolescentes e adultos jovens decorrentes de exposição a ruído social: Meta-análise. Revista CEFAC, 17(6), 2056-2064.

Martin, G.Y., Martin, W.H., Mink, D.M., \& Finan, D. (S. d.) The Jolene Cookbook C - Instruction Guide, Version 3.1. Dangerous decibels. Recuperado de http://dangerousdecibels.org/jolene/cookbook/

Mendonça, J. E., \& Lemos, S. M. A. (2011). Promoção da saú de e ações fonoaudiológicas em educação infantil. Revista CEFAC, 13(6), 1017-1030.

Ministério da Saúde, Ministério da Educação. (S. d.). Promoção da Saúde Auditiva. Recuperado de http://189.28.128.100/dab/docs/portaldab/documentos/pse/orientacao geral saude auditiva.pdf

Nunes, A. D. S. (2018). Prevalência de perda auditiva e fatores associados em escolares da rede pública muniaipal de Natal/RN (Dissertação de Mestrado). Universidade Federal do Rio Grande do Norte, Natal, Brasil. Recuperado de https://repositorio.ufrn.br/handle/123456789/26006

Oliveira, D. D. S., Zamboni, M., da Silva Quevedo, L., \& Daroit, L. (2018). A influência da música amplificada no perfil auditivo de estudantes de ensino médio. Distúrbios da Comunicação, 30(3), 522-533.

Organização Mundial da Saúde (OMS). (2020). World hearing day 2020: Hearing for life. Genebra: Organização Mundial da Saúde (WHO). Recuperado de https://www.who.int/news-room/events/detail/2020/03/03/default-calendar/worldhearing-day-2020-hearing-for-life

Organização Mundial de Saúde (OMS). (2016). Childhood Hearing Loss. Genebra: Organização Mundial da Saúde (WHO). Recuperado de https://www.who.int/pbd/deafness/world-hearing-day/WHD2016 Brochure EN 2.pdf?ua=1

Organização Mundial de Saúde (OMS). (2018). WHO global estimates on prevalence of hearing loss. Genebra: Organização Mundial da Saúde (WHO). Recuperado de https://www.who.int/deafness/estimates/en/

Ramos, M. Y. (2017). Internacionalização da pós-graduação no Brasil: Lógica e mecanismos. Educação e Pesquisa, 44(0), $1-22$.

Rodrigues, A. T., Bertin, V., Vitor, L. G. V., \& Fujisawa, D. S. (2014). Crianças com e sem deficiência auditiva: O equilíbrio na fase escolar. Revista Brasileira de Educação Especial, 20(2), 169-178.

Santos, J. F., Seligman, L., \& Tochetto, T. M. (2012). Conforto acústico na percepção de escolares alfabetizados. Revista da Sociedade Brasileira de Fonoaudiologia, 17(3), 254-259.

Santos, J. H. S., Rocha, B. F., \& Passaglio, K. T. (2016). Extensão universitária e formação no ensino superior. Revista Brasileira de Extensão Universitária, 7(1), 23-28.

Silva, S. S. L. (2018). Principais patologias laríngeas em professores. Distúrbios da Comunicação, 30(4), 767-775.

Schwartz, S. R., Magit, A. E., Rosenfeld, R. M., Ballachanda, B. B., Hackell, J. M., Krouse, H. J., ... \& Walsh, S. (2017). Clinical practice guideline (update): Earwax (cerumen impaction). Otolaryngology-Head and Neck Surgery, 156(1), 1-29. Sobel, J., \& Meikle, M. (2008). Applying health behavior theory to hearing-conservation interventions. Seminars in Hearing, 29(1), 81-89.

Tamanini, D., Ramos, N., Dutra, L. V., \& Bassanesi, H. J. C. (2015). Triagem auditiva escolar: Identificação de alterações auditivas em crianças do primeiro ano do ensino fundamental. Revista CEFAC, 17(5), 1403-1414.

Como citar este artigo:

De Farias, T. R. F., Nunes, A. D. da S., De Barros, V. V., Xavier, A. R. da S., Freire, P. A., Arrais, R. F., Barbosa, I. R., Chung, K., \& Balen, S. A. (2021). Programa Saúde Auditiva do Escolar: Uma integração entre pesquisa e extensão. Revista Brasileira de Extensão Universitária, 12(2), 135-146. https://periodicos.uffs.edu.br/index.php/RBEU/article/view/11736/pdf 